\title{
Four-dimensional model: A literature review on reasons behind lurking
}

\author{
behavior
}

\begin{abstract}
Purpose - In the early days of online communities, researchers tended to view lurkers negatively and considered them illegitimate and peripheral members. However, the tide of opinion about lurkers has gradually become more positive. To take a broad view, lurkers should be included in the knowledge sharing context because while they may not share knowledge directly, they are still stakeholders in online communities who benefit from the knowledge shared. This study reviews the literature from a knowledge sharing perspective to provide a comprehensive understanding of lurkers in online communities and identify additional reasons behind lurking behavior.
\end{abstract}

Design/methodology/approach - Previous studies that examined reasons behind lurking behavior in the literature were reviewed.

Findings - A four-dimensional model is provided which categorizes the additional reasons for lurking into four domains: individual, social, organizational, and technological.

Originality/value - The model serves as a roadmap for future researchers in examining lurkers and lurking behavior. Lurkers should be re-defined. De-lurking strategies were suggested following the reasons for lurking behavior in the four-dimensional model, but de-lurking strategies were not recommended in all circumstances. An increase in active lurkers is another option to bring more value to online communities.

Key words: lurker; online communities; knowledge sharing; literature review

\section{Introduction}

\subsection{Knowledge sharing in online communities}

Knowledge sharing is an activity which is carried out to exchange knowledge, concerning 
information, skills, or experiences among individuals (Nguyen, 2020a; Nguyen, 2020b). With the development of information and communication technologies, and especially of online communities, knowledge sharing is flourishing (Charband \& Navimipour, 2016; Shen et al., 2010). Online communities are communication platforms and social networks for people who have hold the same interests or goals. These communities are guided by formal or informal policies as well as supported by various computer systems and often have unique content because of member-contributed knowledge (Nguyen et al., 2019a; Preece \& MaloneyKrichmar, 2005). Access to knowledge is cited as the most common reason for joining an online community (Ridings \& Gefen, 2004; Yoon \& Rolland, 2012). Therefore, online communities which have compelling content often attract more members, creating a loop as more members generate more content to draw in more members. In this way, knowledge generated in online communities becomes a valuable currency or social resource (Ridings et al., 2006). However, in examining knowledge sharing in online communities, the focus of prior researchers has been on determinants of knowledge sharing with a lack of studies investigating the different types of participant in the online knowledge sharing process (Nguyen et al., 2019b; Nguyen et al., 2019c; Nguyen, 2020a).

\subsection{Lurkers in online knowledge sharing}

Participants in online communities are often categorized into two types: lurkers and posters. The former refers to those who read postings without making their own contribution while the latter refers to those who share knowledge online (Nguyen, 2020a). Although posters often donate knowledge to build value, the vast majority of members in many online communities are lurkers, accounting for up to ninety percent of the total number of participants (Cranefield et al., 2015; Marett \& Joshi, 2009). This phenomenon has drawn the attention of research communities to understand what underpins lurking behavior. The main focuses of prior 
researchers are often related to identifying lurkers, reasons for lurking, and methods to deal with lurkers (see the reviews of Sun et al., 2014 and Amichai-Hamburger et al., 2016). Interestingly, past researchers tended to have a negative view of lurkers (Preece et al., 2004). Therefore, de-lurking strategies, which encourage lurkers to become posters, have been proposed to reduce the number of lurkers in online communities. However, whether lurking is always inappropriate behavior and whether de-lurking strategies are the best ways to add more value to online communities are issues that need more investigation.

The lurking phenomenon has long been seen as an enigma since the vast majority of participants in many online communities are lurkers (Phang et al., 2009). Identifying reasons for lurking is crucial to understand lurkers, who account for the majority of online participants. When examining lurking behavior, it seems that prior researchers have often focused on psychological reasons. However, previous researchers tended to decline to locate lurkers in the knowledge sharing context. Although lurkers are not active in posting, they are also stakeholders in the knowledge sharing process. From a knowledge sharing perspective, knowledge is the value that attracts members to online communities. If lurking behavior is not examined in the knowledge sharing context, reasons underpinning lurking behavior may be missed, which could lead to difficulties in fully understanding lurker behavior. Therefore, this raises a question of whether the literature has adequately identified the reasons for lurking, and if from the knowledge sharing perspective, there are additional reasons underpinning lurker behavior.

\subsection{Aim and significance of the review}

In response to the growing number of online communities as well as a need to understand the reasons for lurking and locate lurkers in the knowledge sharing context, this study reviews the existing lurking literature and provides a new view of lurkers. In particular, this study 
systematically examines and synthesizes the existing literature concerning the reasons behind lurking behavior, to map out what has been explored and what needs to be investigated further. By doing so, the significance of this study is threefold (see Figure 1): First, the study provides a comprehensive picture of lurkers in knowledge sharing in online communities, through which this study can bring an objective view about lurkers and lurking behavior. Second, the study provides additional reasons behind lurking behavior from the knowledge sharing perspective, which have not been examined or clearly highlighted in the literature. Third, by mapping what has already been investigated, the study shows research gaps and proposes suggestions for future research.

Insert Figure 1 here

\section{Methods}

This literature review consisted of three phases. The research was started by reviewing relevant articles from the literature to capture the reasons behind lurking behavior in knowledge sharing in online communities. In the second phase, based on the reasons from the literature, the reasons behind lurking behavior were systematically summarized. In the last phase, the proposed conceptual model with reproducible, rigorous and comprehensive approaches will be developed and finalized to gain a deeper understanding of key additional reasons behind lurking behavior which has not been identified in previous reviews. The value of a literature review approach is to show the reach of the literature across sizable and heterogeneous studies through a process of extraction and synthesis, and thus shed light on research gaps in the literature (Pickering et al., 2015). As the aims of the study are to map the landscapes and boundaries of lurkers in knowledge sharing in online communities as well as reveal research gaps for future studies, a literature review is deemed a suitable tool. 


\section{Review findings}

\subsection{Defining lurker}

Researchers have formulated various definitions of lurkers. However, the term 'lurker' is not an absolute term and there is no unified definition. A strict definition of a lurker is a member who has never posted (Preece et al., 2004). However, the term 'lurker' may also refer to members who post infrequently, have not posted recently, maintain a minimal level of posting, such as fewer than four posts over a twelve-week period, or contribute fewer than the average number of postings (Preece et al., 2004; Ridings et al., 2006).

In the early days, researchers tended to view lurkers negatively (Wasko \& Faraj, 2005; Wasko et al., 2009). Lurkers were considered to be illegitimate and peripheral members in online communities and pose a problem for posters (Preece et al., 2004). If posters see that the majority of members are lurking rather than participating in a discussion and contributing, they may be discouraged from sharing, or feel that they are being spied upon. In addition, lurkers were regarded as free-riders who wasted valuable bandwidth while benefiting from the knowledge posted in online communities or using content without seeking consent (Nonnecke et al., 2006). As a consequence, lurking, which often refers to lurkers' activity in online communities, was regarded as inappropriate behavior or detrimental use of technology. In other words, the social capital of online communities deemed to be drained by lurkers, and thus effort was needed to prevent lurking (Preece et al., 2004). The sustainability of an online community requires contributions from participants, but lurkers merely observe others' interactions and benefit from the information posted. This can become quite extreme when lurkers are noticeable in intimate communities such as chat rooms. In an experiment by Hudson and Bruckman (2004), 29\% of chat rooms showed a disregard for lurkers by kicking them out because they did not post anything. 
Recently, the tide of opinion about lurkers has changed to one that is more positive. Lurkers are accepted as community members (Preece et al., 2004) and may learn vicariously through posters (Preece et al., 2004). However, the term 'free-rider' may still be used to characterize those who lurk (Wasko \& Faraj, 2005; Wasko et al., 2009). In addition, due to the high number of lurkers in online communities, reasons for lurking behavior have been paid significant attention from both researchers and practitioners.

\subsection{Four-dimensional model of lurking}

The literature recognizes the existence of a variety of reasons behind lurking behavior (see reviews of Sun et al., 2014 and Amichai-Hamburger et al., 2016). However, what is missing in the literature is an investigation of lurking behavior in a knowledge sharing context. Individuals participate in online communities mainly because of knowledge demand (Ridings \& Gefen, 2004; Yoon \& Rolland, 2012). After the process of literature review, some key additional reasons were found to lead to lurking behavior. Based on the four-dimensional model of (Nguyen, 2020a), the additional reasons behind lurking behavior in this study are categorized into four groups in the individual-social-organizational-technological (ISTO) model (see Figure 2). According to Nguyen (2020a), the decision to share knowledge or lurk is based on four categories of factors: individual, social, organizational, and technological. Individual factors are the individual characteristics that help to explain why different people behave differently in the same situation. Social, organizational, and technological factors explain the response of individuals under the influences of external determinants. A four-dimensional model provides a comprehensive picture for overall additional reasons behind lurking behaviorization. The following sections describe these four groups in the ISTO model for lurking in detail. 
Insert Figure 2 here

\subsubsection{Individual factors}

Individual factors relate to members' perceptions about their cognitive needs, knowledge selfefficacy and loss of knowledge power. Cognitive needs refer to individual cognition about the need for knowledge and the necessity of posting. Regarding the need for knowledge, participants tend to lurk when they feel that their knowledge needs are fulfilled by lurking. When a member participates in an online community, they often do so with a specific need for specific information or to find a solution to an issue (Ridings \& Gefen, 2004; Yoon \& Rolland, 2012). If they can find all the information they need or the answer to solve an issue, they may think that they do not need to post as reading or browsing suffices (Merry \& Simon, 2012; Nonnecke et al., 2006; Park \& Gabbard, 2018). In terms of the necessity of posting, members who think it is not necessary to post (Merry \& Simon, 2012; Nonnecke et al., 2006; Park \& Gabbard, 2018; Preece et al., 2004) or have no interest in posting and find posting annoying (Merry \& Simon, 2012; Nonnecke et al., 2006; Park \& Gabbard, 2018; Simon et al., 2013) often lurk. As posting is not compulsory in online communities, such members do not find posting necessary or of benefit to them (Nonnecke et al., 2006; Preece et al., 2004).

Knowledge self-efficacy refers to an individual's confidence in their ability to provide valuable knowledge to others (Nguyen, 2020a). An individual who has low knowledge selfefficacy is likely to lurk (Gray, 2004). In order to post, individuals need to have a certain knowledge about the topic under discussion. Otherwise, they may feel embarrassed when their posting does not provide value or make much of a contribution. The coordinators of community-based adult learning programs in the study by Gray (2004) felt that they lacked specific experience to share and so had nothing to offer, leading to lurking behavior. Some members in MSN bulletin board communities in a study by Preece et al. (2004) were not 
confident about their knowledge to post or contribute anything to online communities, and therefore tended to lurk. The same reason for lurking behavior is given in the studies by Nonnecke et al. (2006), Park and Gabbard (2018), and Simon et al. (2013) by members who thought that they could not contribute value to online communities and did not perceive the importance of their participation. Lurkers in LiveJournal communities agreed that they did not know enough about the topic to contribute (Merry \& Simon, 2012), resulting in lurking behavior. In addition, the lack of ability to self-express may also lead to lurking. Some members of online health support groups struggled with self-expression, so they remained silent (Fullwood et al., 2019).

Another significant individual factor impacting active lurker behavior is perceived loss of knowledge power (Bishop, 2011; Xiang et al., 2013). In a knowledge-based society, knowledge has been chosen as the most strategically important resource (Cantu et al., 2009; De la Vega \& Stankosky, 2010; Grant, 1996) and a principal source of value creation (Nonaka, 1991; Spender \& Grant, 1996; Teece et al., 1997). Individuals may feel a sense of threat to their competitive advantage, power, importance and job security by sharing information with others. Due to this threat, they are more likely to hoard knowledge as a way to maintain power, advance career opportunities and increase salary options (Bishop, 2011). Thus, lurking in online communities presents value to such members as critical knowledge, expertise and innovation development can be obtained, without having to reciprocate.

\subsubsection{Social factors}

Social factors are related to the interaction with other members in online communities. Social interaction ties, trust and volume of posting are social reasons for lurking that have been paid insufficient attention in previous studies. Social interaction ties refer to the bond among members of the online community (Garrett \& Caldwell, 2002). Close social interaction ties, as 
exemplified by posters, are shown to have a positive influence on knowledge sharing because participants increase their depth, breadth, and efficiency of knowledge sharing (Amayah, 2013). In contrast, members tend to be lurkers if they do not have close social interaction ties with other members in the online community (Chow \& Chan, 2008; Liu et al., 2015; Zhao et al., 2013). Previous studies (Chow \& Chan, 2008; Liu et al., 2015; Zhao et al., 2013) have proven that if relationships among participants are not close, members tend not to be willing to share knowledge and prefer to lurk rather than post. Furthermore, low interaction such as little attention and insufficient encouragement from other members in an online community may discourage members from posting again (Nonnecke et al., 2006; Preece et al., 2004). Members who are concerned about receiving aggressive or hostile responses or see groups treating members badly or worry about their messages being ignored tend to lurk (Merry \& Simon, 2012; Nonnecke et al., 2006; Park \& Gabbard, 2018). Some members in the study by Simon et al. (2013) felt uncomfortable communicating with other members and therefore did not want to discuss the topic or contribute to the online community.

Lack of trust is another reason for lurking (Yang \& Chen, 2007). From the view of Social Exchange Theory, if participants do not trust others, they are not willing to participate in social exchange (Gammelgaard, 2010; Nguyen et al., 2015; Zhao et al., 2013). In the studies by Ridings et al. (2006) and Rau et al. (2008), lurkers had less trust in others' benevolence and integrity than posters. Likewise, due to misgivings about other participants, they do not contribute their knowledge. As a result of this lower level of trust, lurkers are reluctant to participate in conversations in online communities (Chen \& Hung, 2010). In addition, new members often develop trust in the community via lurking to become more familiar with the group. Such members may be posters in other groups because they know other members, but in a new community, they may wish to lurk first to build up trust (Preece et al., 2004).

The volume of posting also influences lurking behavior. Lurkers may choose not to post 
in reaction to information overload or due to the lack of or delay in response (Preece et al., 2004). The overwhelming number of posts or poor quality of information and knowledge shared in the online community is also found to be a cause of lurking behavior (Merry \& Simon, 2012; Nonnecke et al., 2006; Park \& Gabbard, 2018; Preece et al., 2004; Simon et al., 2013). In the context of health, new members read content and learn forum norms before contribution because they want to ensure that they do not waste other people's time where people in the forums are gravely ill (Costello, 2017). New members of health fora in the study by Costello (2017) do not want to repeat questions; therefore, they read previous posts to understand the community before posting. Lurking, in this case, could be interpreted as a way of not offending others' feelings and showing respect.

\subsubsection{Technological factors}

Technological factors are related to technological reasons preventing users from posting. Previous studies seem to have focused on the quality of technical design rather than perception of users (Amichai-Hamburger et al., 2016). Low level of perceived ease of use is also a barrier. According to the technology acceptance model, all things being equal, improvements in ease of use will lead to improvements in performance (Davis et al., 1989; Nguyen et al., 2013). This means that if members do not know how to operate a system or post, they will not want to contribute knowledge. In the study by Preece et al. (2004), 7.8 percent of respondents reported that the reason for their silence was the difficulty in posting online. The findings of the studies by Preece et al. (2004) and Nonnecke et al. (2006) also showed that some members did not know how to post in the online community, thus leading to lurking behavior. Yen (2016) and Nguyen et al. (2013) argue that an online platform for knowledge sharing of online communities is becoming more sophisticated due to advances in information technology. The constant development of online platforms may be challenging for users. 
Online communities often have different types of member; therefore, multi-functions can match different demands and needs of members (Guilhermino Trindade et al., 2012). Limited functionability can inconvenience members or make it hard for them to engage, thus leading to lurking rather than contributing knowledge. Some members may wish to protect their reputation and do not want to attract attention from others. If online communities do not offer an anonymous function, lurking is often their preferred behavior (Fan et al., 2009). They are inclined to lurk to avoid annoyance from persistent messages as a result of posting (Nonnecke \& Preece, 2001). Lurking facilitates an ability to remain incognito as a means to detract from over scrutiny or involvement in blame wars within the online community (Chennamaneni et al., 2012). In this context, lurking becomes a preferable choice which simultaneously enables issue avoidance, the maintainance of reputation, self-preservation and anonymity.

\subsubsection{Organizational factors}

Any online community also has an organizational structure, norms and rules; therefore, these factors will affect lurking behavior through community management and commitment. Community management can be categorized as a determinant of lurking behavior, although it has not received much attention by researchers in the literature. Management support is crucial in creating a favorable environment for members, especially in large or multi-national online communities (Cavaliere \& Lombardi, 2015). For example, management should demonstrate their roles in restricting unfriendly responses or helping new members. Conflicts among members also require intervention by management. Online communities with poor management may lead to a mess in knowledge shared and discourage members. Without support from management to connect with others, members may feel lost and lose interest in the contribution of knowledge (Han et al., 2014; Han et al., 2012). Poor management support has a negative impact on members, leading to lurking behavior. In the study by Preece et al. 
(2004), some members lurked because they felt online community managers made little effort for the community. Sometimes, online community managers let aggressive messages appear in the online community, which insult other members and compromise the whole community.

Low level of commitment is another reason for lurking. Commitment refers to the relative strength of an individual's identification in online communities (Shen et al., 2010; Xiang et al., 2013; Yen, 2016). A participant with a low level of commitment often prefers to lurk rather than share knowledge (Tsai \& Cheng, 2012). Low commitment may happen to members who want to be free from duties or have no feeling of belongingness and attachment to online communities. Commitment to online communities often requires time and effort; thus, not all members want to invest much time and effort into voluntary tasks in online communities (Nguyen, 2020a). Such members often lurk because they may fear that if they posted, they were making a commitment.

The level of commitment also depends on the organizationl context: an organizational setting or an open system (Nguyen et al., 2019a). In open systems where online communites are open for anyone to participate in, the level of commitment is often lower because knowledge sharing is voluntary, members often do not get punished for their lurking. In contrast, in organizational settings where only employees can join, the level of commitment is often higher because individuals belong to the same organization and have close relationships with co-workers, leading to knowledge sharing rather than lurking (Nguyen et al., 2019a). In addition, lurking could lead to negative consequences such as organizational inefficiency or fragmentation of services and/or service breakdown; thus, employees tend to minimize lurking behavior (Nguyen, 2020a). Furthermore, in organizational settings, as parts of work requirements for some jobs or positions such as trainers or supervisors, employees tend to less commit lurking due to job security (Nguyen et al., 2019c; Nguyen, 2020b). 


\section{Discussion and future research suggestions}

The aim of this study is to investigate the reasons underpinning lurking behavior in online knowledge sharing. From the review findings, there are some issues which need to be discussed as follows.

\subsection{Re-defining lurkers}

Lurkers should be re-defined in online communities. Traditional approaches viewed lurkers as invisible members or peripheral players. However, in the lurking literature, the reasons behind lurker behavior have not been reviewed comprehensively as lurkers have not been examined from a knowledge sharing context. Since lurkers are regarded as stakeholders in the knowledge sharing process, so from the knowledge sharing perspective, additional reasons for lurking have been pointed out in the ISTO model. These reasons show that lurkers should be re-defined lurkers in a positive way.

Lurkers are not non-users, but active and goal-driven participants, engaging in different activities as well as employing a range of strategies (Edelmann, 2013). Lurkers may actually spend many hours lurking to read information even though they infrequently or never post. From the onset, participants may not actually intend to lurk (Sun et al., 2014). Due to some reasons that is shown in the ISTO model such as low interaction ties, poor community management, low perceived ease of use and limited functions of the systems, these lead to lurking behavior. Furthermore, lurking may help to reduce the overload of information caused by a repetition of queries and an overload of information that could occur if all members posted (Preece et al., 2004). In the study by Alexandrov et al. (2013), they emphasise the importance of lurkers when the online community is dominated by negative comments. They found that high poster rates are harmful if negative comments prevail because posters' attitudes and brand buying intentions are strongly impacted by what the community thinks. Consequently, if 
negative comments prevail, organizations should try to discourage posters postings and contend with lurkers, who are generally more indifferent toward what other users say.

Lurkers do have their own opinions and ideas (Amichai-Hamburger, et al., 2016). They may have the ability to contribute valuable knowledge, but they may be waiting to get used to the communities, develop a feeling of belonging and build up trust before contributing (Ridings et al., 2006). Even if lurkers do not possess value knowledge, they also can learn from the knowledge shared by other participants to increase self-efficacy to become posters in the future, providing key revenue resources and valuable information and knowledge (Ridings et al., 2006). In a large community, lurking may be advantageous because it helps to avoid the same questions being asked repeatedly and ensures the relevance of postings (Preece et al., 2004). Ridings et al. (2006) argue that lurking is certainly desirable to keep a balance in online communities. For example, in online communities with several thousand members, although these communities still need to have a certain number of posters to generate content and maintain value, if every member posted daily or weekly, information overload could follow (Ridings et al., 2006). In the online communities which survive by sponsorship or advertising, the role of lurkers is as valuable as posters since revenue depends upon the number of visits rather than postings. Thus, lurking should be viewed in a positive way and lurkers should not be seen as 'selfish free-riders' (Edelmann, 2013). Misunderstanding lurking may be detrimental to the ethos of an online community.

\subsection{De-lurking strategies}

In online communities, the existence of lurkers has a certain role; however, a preponderance of lurkers may result in a low posting rate and low-value content. In order to maintain sustainability, assisting and encouraging lurkers to transition to active posters is important. In the literature, de-lurking strategies, which encourage lurkers to post, have been suggested. In 
line with four groups of additional reasons of lurking in the ISTO model, namely individual, social, organizational and technological, this study proposes ISTO de-lurking strategies into four types accordingly as described in Figure 3.

Insert Figure 3 here

Regarding individual strategies, changing belief is one option for those who have low cognitive needs. Such participants often believe that posting is not necessary, which prevents them from carrying out their desires to be social and participate in discussions. Thus, changing beliefs is a potential solution even though it may create a degree of dissonance with participants' cognition. To do this, two means are suggested, persuasive text and perceived affordance (Bishop, 2007). Regarding the use of persuasive text, new information dissonant with lurkers' existing beliefs is provided. Lurkers may examine the information concerning the credibility of the source before changing their beliefs and cognition, such as goals (Nguyen, 2020a). Challenging beliefs may persuade lurkers to participate in discussion in online communities. Using mediating artefacts to offer perceived affordances is an alternative option (Bishop, 2007). In this way, lurkers may become more actively engaged in a state of flow and exhibit intemperance or even deference (Bishop, 2007). Furthermore, for some lurkers who think about knowledge power, a message of encouragement may be useful. This can be in the form of a welcome message, stating that any enquiries or comments are encouraged.

In terms of social strategies, trust enhancement is very important, especially in online communities. In line with previous studies, Bishop (2007) and Ridings et al. (2006) suggest using a rating system which permits participants to evaluate postings both in terms of quality relevance and quantity. This system may help lurkers to assess credibility, thus changing their beliefs and encouraging them to engage in posting either through a direct message on the forum or via email. Another way to encourage participation could be to include voting on topics as a 
low-risk way for lurkers to start to contribute (Ridings et al., 2006). Furthermore, in order to encourage social interaction ties, online communities should ensure that the environment is friendly, so participants feel comfortable in discussions (Nguyen, 2020b). Impolite responses or negative postings should be prevented and controlled by protocols, which should increase the free interaction among participants (Nguyen et al., 2019a). In addition, community responses to newcomers are very important to encourage them to participate. Welcome feedback and support can be given to encourage new members (Malinen, 2015).

A range of technological strategies may also be applied to encourage lurkers to become posters and share knowledge. Usability improvement is one technological solution for those who have low perceived ease of use. A user-friendly interface is very important to motivate participants, especially newcomers (Nguyen, 2020b; Preece et al., 2004). Online communities can simplify the posting procedure or make tutorial videos to guide members through all functions. Usability support is also very helpful, especially for familiarization with the system (Preece et al., 2004). Another suggested strategy is the deployment of a simpler web structure with a minimum number of hyperlinks. This will help members who prefer closure to feel comfortable in the online discussion environment (Amichai-Hamburger et al., 2016). To deal with very active discussions, a zooming interface that allows users to view a map of content, then navigate or zoom into areas of interest is a strategy (Ridings et al., 2006). Maintaining multi-functions for online community is also crucial for online communities to increase the numbers of posters. For example, online communities may offer an option of anonymity and a strong feeling of stability of the systems in which online communities are set up to encourage participants to contribute to online discussions.

Using incentives and guidance for newcomers are organizational strategies for delurking. Social Exchange Theory suggests that individuals will be more active in knowledge sharing if they are offered incentives such as financial rewards, bonds, and gifts (Constant et 
al., 1994; Nguyen et al, 2019a; Nguyen, 2020b) or praise for weekly top contributors. This strategy has been applied in order to encourage lurkers to commit and bring valuable knowledge to online communities (Hummel et al., 2005). Either controlling or informative rewards are an effective means to promote knowledge contribution. In addition, Bishop (2007) believes that management support including leader and senior user support is one of the most effective means to encourage more active participation. Since lurkers can be persuaded to join a discussion if they see that their postings are responded to in a constructive way, a leader could send a private message to lurkers to encourage them and connect participants of online communities, leading to an essential need to be present (Bishop, 2007). Another strategy is to introduce new members or invite them to introduce themselves to make them feel welcome (Ridings et al., 2006). Offering a mentor or online buddy to support new members is another de-lurking strategy (Ridings et al., 2006). As newcomers often need time to become familiar with a new environment, online communities should provide guidance and introduce new members. Help and support from administrators and older members are very useful in encouraging newcomers to become active in posting.

\subsection{Value of active lurkers}

Although de-lurking strategies can encourage lurkers to become posters, the shift from lurking to posting, de-lurking, is not always the most important way to make online communities more valuable. Lurking can also bring benefits to online communities since lurkers, as indirect contributors, propagate the topics to other communities, and use the information or knowledge gained to apply to other activities. This kind of lurkers can be called active lurkers who make direct contact with posters and propagate knowledge in online communities (Takahashi et al., 2003). While an increase in the number of active posters could lead to information overload, an increase in active lurkers may be more effective (Edelmann, 2013). Furthermore, 
participating in an online community does not only include posting but also lurking. Lurking contributes by reading, editing and organising others' postings. Even if lurkers do not use or propagate knowledge gained, their thoughts can be changed as a result of the influence of online communities (Edelmann, 2013). Future researchers can consider examining active lurkers and the ways to encourage active lurkers to propagate to other communities.

\subsection{Capture of lurking behavior}

Previous researchers have not captured lurking behavior in the empirical quantitative studies. Instead, prior researchers often categorize participants into two groups, posters and lurkers, and compare the impact from determinants on knowledge sharing behavior between the two groups such as Schultz and Beach (2004) or Hung et al. (2015). Interestingly, the criteria for such categorization is often based on the lurker definition in which lurkers are those who had never posted a message (Bartikowski \& Walsh, 2014; Lai \& Chen, 2014; Liao \& Chou, 2012). As there is no unified definition of lurkers, the adoption of such an absolute definition of lurkers probably indicates that empirical studies cannot cover all lurkers' behavior. Relying on the number of posting to categorize participants (i.e. people post or not post) in order to compare their knowledge sharing behavior may be an oversimplification of their actual behavior. Despite various attempts to examine knowledge sharing behavior from different aspects (Chen \& Hung, 2010), none has investigated lurking behavior. As lurking should be considered as a common online behavior, a new variable, 'lurking', should be constructed in the knowledge sharing process in empirical quantitative studies (Nguyen, 2020a).

\subsection{Longitudinal and cross-community studies}

Previous studies have identified reasons for lurking and proposed numerous de-lurking strategies to encourage lurkers to become posters. However, the effect of de-lurking strategies is longitudinal. There has not been a longitudinal study to observe the change of lurkers and 
the effect of de-lurking strategies. On the other hand, as de-lurking is not the only way to make online communities have more value, active lurkers also play an important role in propagation. In fact, there are lack of studies examining how active lurkers can contribute to online communities. In addition, as individuals often participate in a number of online communities simultaneously, there is a case in which they are lurkers in one online community but posters in others. Future studies should place more attention to cross-community to examine individual behavior across online communities.

Another point that needs to be discussed is that occasions exist in which posters may become lurkers when they lose their motivation or interest. For example, an expert may not wish to expose their ignorance or have their reputation attacked (Preece et al., 2004). Previous studies have shown that posters and lurkers are somewhat different regarding their motivation for knowledge sharing behavior in online communities; thus, strategies for each group should be tailors accordingly. Future researchers should consider investigating inter-conversion between lurkers and posters.

\section{Conclusion}

Understanding what behind lurker behavior is very important because lurkers account for the majority of online members. This study has contributed to the literature by putting lurkers into the knowledge sharing context to propose the ISTO model for lurking in which the additional reasons behind lurking behavior are highlighted. From the model, lurkers are recommended to be viewed in a positive view. Following the ISTO model for luring, the ISTO de-lurking strategies were suggested. However, de-lurking strategies are not always the most effective. An increase in active lurkers is another way to bring more value to online communities. Future researchers should consider empirically validating the ISTO model for lurking and the ISTO de-lurking strategies to validate these models and provide further understanding lurking behavior in online communites. 


\section{References}

Alexandrov, A., Lilly, B., \& Babakus, E. (2013). The effects of social- and self-motives on the intentions to share positive and negative word of mouth. Journal of the Academy of Marketing Science, 41(5), 531-546. doi:10.1007/s11747-012-0323-4

Amayah, A. T. (2013). Determinants of knowledge sharing in a public sector organization. Journal of Knowledge Management, 17(3), 454-471. doi:10.1108/JKM-11-2012-0369

Amichai-Hamburger, Y., Gazit, T., Bar-Ilan, J., Perez, O., Aharony, N., Bronstein, J., \& Dyne, T. S. (2016). Psychological factors behind the lack of participation in online discussions. Computers in Human Behavior, 55, 268-277. doi:10.1016/j.chb.2015.09.009

Bartikowski, B., \& Walsh, G. (2014). Attitude contagion in consumer opinion platforms: posters and lurkers. Electronic Markets, 24(3), 207-217. doi:10.1007/s12525-013$0149-\mathrm{z}$

Bishop, J. (2007). Increasing participation in online communities: A framework for humancomputer interaction. Computers in Human Behavior, 23(4), 1881-1893. doi:10.1016/j.chb.2005.11.004

Bishop, J. (2011). Transforming lurkers into posters: The role of the participation continuum. Paper presented at the Proceedings of the Fourth International Conference on Internet Technologies and Applications (ITA11).

Cantu, F. J., Bustani, A., Molina, A., \& Moreira, H. (2009). A knowledge-based development model: the research chair strategy. Journal of Knowledge Management, 13(1), 154170. doi:10.1108/13673270910931233

Cavaliere, V., \& Lombardi, S. (2015). Exploring different cultural configurations: how do they affect subsidiaries' knowledge sharing behaviors? Journal of Knowledge Management, 19(2), 141-163. doi:10.1108/JKM-04-2014-0167 
Charband, Y., \& Navimipour, N. J. (2016). Online knowledge sharing mechanisms: A systematic review of the state of the art literature and recommendations for future research. Information Systems Frontiers, 18(6), 1131-1151. doi:10.1007/s10796-016$9628-\mathrm{z}$

Chen, C. J., \& Hung, S. W. (2010). To give or to receive? Factors influencing members' knowledge sharing and community promotion in professional virtual communities. Information \& Management, 47(4), 226-236. doi:10.1016/j.im.2010.03.001

Chennamaneni, A., Teng, J. T., \& Raja, M. (2012). A unified model of knowledge sharing behaviors: theoretical development and empirical test. Behavior \& Information Technology, 31(11), 1097-1115. doi:10.1080/0144929X.2011.624637

Chow, W. S., \& Chan, L. S. (2008). Social network, social trust and shared goals in organizational knowledge sharing. Information \& Management, 45(7), 458-465. doi:10.1016/j.im.2008.06.007

Constant, D., Kiesler, S., \& Sproull, L. (1994). What's mine is ours, or is it? A study of attitudes about information sharing. Information Systems Research, 5(4), 400-421. doi:10.1287/isre.5.4.400

Costello, K. L. (2017). Social relevance assessments for virtual worlds. Journal of Documentation, 73(6), 1209-1227. doi:http://dx.doi.org/10.1108/JD-07-2016-0096

Cranefield, J., Yoong, P., \& Huff, S. L. (2015). Rethinking Lurking: Invisible leading and following in a knowledge transfer ecosystem. Journal of the Association for Information Systems, 16(4), 213.

Davis, F. D., Bagozzi, R. P., \& Warshaw, P. R. (1989). User acceptance of computer technology: a comparison of two theoretical models. Management Science, 35(8), 982-1003. doi:10.1287/mnsc.35.8.982 
De la Vega, A. F. R., \& Stankosky, M. (2010). Knowledge management and innovation: What must governments do to increase innovation? Search of Knowledge Management: Pursuing Primary Principles, 275.

Edelmann, N. (2013). Reviewing the definitions of "lurkers" and some implications for online research. Cyberpsychology, Behavior, and Social Networking, 16(9), 645-649. doi:10.1089/cyber.2012.0362

Fan, Y. W., Wu, C. C., \& Chiang, L. C. (2009). Knowledge sharing in virtual community: The comparison between contributors and lurkers. Paper presented at the The 9th international conference on electronic business. Macau.

Fullwood, C., Chadwick, D., Keep, M., Attrill-Smith, A., Asbury, T., \& Kirwan, G. (2019). Lurking towards empowerment: Explaining propensity to engage with online health support groups and its association with positive outcomes. Computers in Human Behavior, 90, 131-140. doi:https://doi.org/10.1016/j.chb.2018.08.037

Gammelgaard, J. (2010). Knowledge retrieval through virtual communities of practice. Behavior \& Information Technology, 29(4), 349-362. doi:10.1080/01449290903548406

Garrett, S., \& Caldwell, B. (2002). Describing functional requirements for knowledge sharing communities. Behavior \& Information Technology, 21(5), 359-364. doi:10.1080/0144929021000050265

Grant, R. M. (1996). Toward a knowledge-based theory of the firm. Strategic Management Journal, 17(S2), 109-122. doi:10.1002/smj.4250171110

Gray, B. (2004). Informal Learning in an Online Community of Practice. Journal of Distance Education, 19(1), 20-35.

Guilhermino Trindade, D. d. F., Guimarães, C., Antunes, D. R., Sánchez Garcia, L., Lopes da Silva, R. A., \& Fernandes, S. (2012). Challenges of knowledge management and 
creation in communities of practice organizations of Deaf and non-Deaf members: requirements for a Web platform. Behavior \& Information Technology, 31(8), 799810. doi:10.1080/0144929X.2011.650712

Han, J. Y., Hou, J., Kim, E., \& Gustafson, D. H. (2014). Lurking as an active participation process: a longitudinal investigation of engagement with an online cancer support group. Health communication, 29(9), 911-923. doi:10.1080/10410236.2013.816911

Han, J. Y., Kim, J. H., Yoon, H. J., Shim, M., McTavish, F. M., \& Gustafson, D. H. (2012). Social and psychological determinants of levels of engagement with an online breast cancer support group: posters, lurkers, and nonusers. Journal of health communication, 17(3), 356-371. doi:10.1080/10810730.2011.585696

Hudson, J. M., \& Bruckman, A. (2004). "Go Away": Participant objections to being studied and the ethics of chatroom research. The Information Society, 20(2), 127-139. doi:10.1080/01972240490423030

Hummel, H. G., Burgos, D., Tattersall, C., Brouns, F., Kurvers, H., \& Koper, R. (2005). Encouraging contributions in learning networks using incentive mechanisms. Journal of computer assisted learning, 21(5), 355-365. doi:10.1111/j.1365-2729.2005.00140.x

Hung, S. Y., Lai, H. M., \& Chou, Y. C. (2015). Knowledge-sharing intention in professional virtual communities: A comparison between posters and lurkers. Journal of the Association for Information Science and Technology, 66(12), 2494-2510. doi:10.1002/asi.23339

Lai, H. M., \& Chen, T. T. (2014). Knowledge sharing in interest online communities: A comparison of posters and lurkers. Computers in Human Behavior, 35, 295-306. doi:10.1016/j.chb.2014.02.004 
Liao, S., \& Chou, E.-y. (2012). Intention to adopt knowledge through virtual communities: posters vs lurkers. Online Information Review, 36(3), 442-461. doi: $10.1108 / 14684521211241440$

Liu, J., Rau, P.-L. P., \& Wendler, N. (2015). Trust and online information-sharing in close relationships: a cross-cultural perspective. Behavior \& Information Technology, 34(4), 363-374. doi:10.1080/0144929X.2014.937458

Malinen, S. (2015). Understanding user participation in online communities: A systematic literature review of empirical studies. Computers in Human Behavior, 46, 228-238. doi:10.1177/0093650211408593

Marett, K., \& Joshi, K. (2009). The decision to share information and rumors: Examining the role of motivation in an online discussion forum. Communications of the Association for information systems, 24(1), 47-68.

Merry, S. K., \& Simon, A. (2012). Living and lurking on LiveJournalThe benefits of active and non-active membership. Aslib Proceedings, 64(3), 241-261. doi:10.1108/00012531211244527

Nguyen, T.-M. (2020a). Four-dimensional model: A literature review in online organizational knowledge sharing VINE Journal of Information and Knowledge Management Systems, forthcoming.

Nguyen, T.-M. (2020b). Do extrinsic motivation and organizational culture additively strengthen intrinsic motivation in online knowledge sharing?: An empirical study. VINE Journal of Information and Knowledge Management Systems, 50(1), 75-93. doi:10.1108/VJIKMS-02-2019-0019

Nguyen, T.-M., Nham, T. P., Froese, F. J., \& Malik, A. (2019a). Motivation and knowledge sharing: a meta-analysis of main and moderating effects. Journal of Knowledge Management, 23(5), 998-1016. doi:10.1108/JKM-01-2019-0029 
Nguyen, T.-M., Nham, P. T., \& Hoang, V.-N. (2019b). The theory of planned behavior and knowledge sharing: A systematic review and meta-analytic structural equation modelling. VINE Journal of Information and Knowledge Management Systems, 49(1), 76-94. doi:10.1108/VJIKMS-10-2018-0086

Nguyen, T.-M., Dinh, V. T., \& Nham, P. T. (2019c). Online knowledge sharing in Vietnamese tele-communication companies: An integration of social psychology models. Knowledge Management \& E-Learning, 11(4), 497-521.

Nguyen, T.-M., Yoshi, T., \& Tuan, N. P. (2015). Determinants of Online Customer Satisfaction in an Emerging Market-a Mediator Role of Trust. International Journal of Contemporary Management, 13(1).

Nguyen, T. T. M., Yoshi, T., \& Nham, P. T. (2013). Technology acceptance model and the paths to online customer loyalty in an emerging market. Tržište, 25(2), 231-248.

Nonaka, I. (1991). The Knowledge-Creating Company Harvard Business Review NovemberDecember.

Nonnecke, B., Andrews, D., \& Preece, J. (2006). Non-public and public online community participation: Needs, attitudes and behavior. Electronic Commerce Research, 6(1), 720. doi:10.1007/s10660-006-5985-x

Nonnecke, B., \& Preece, J. (2001). Why lurkers lurk. Paper presented at the AMCIS 2001 Proceedings.

Park, J., \& Gabbard, J. L. (2018). Factors that affect scientists' knowledge sharing behavior in health and life sciences research communities: Differences between explicit and implicit knowledge. Computers in Human Behavior, 78, 326-335. doi:https://doi.org/10.1016/j.chb.2017.09.017 
Phang, C. W., Kankanhalli, A., \& Kabhrwak, R. (2009). Usability and sociability in online communities: A comparative study of knowledge seeking and contribution. Journal of the Association for Information Systems, 10(10), 721-747.

Pickering, C., Grignon, J., Steven, R., Guitart, D., \& Byrne, J. (2015). Publishing not perishing: How research students transition from novice to knowledgeable using systematic quantitative literature reviews. Studies in Higher Education, 40(10), 17561769. doi:10.1080/03075079.2014.914907

Preece, J., \& Maloney-Krichmar, D. (2005). Online communities: Design, theory, and practice. Journal OF Computer-Mediated Communication, 10(4), Article 1. doi:10.1111/j.1083-6101.2005.tb00264.x

Preece, J., Nonnecke, B., \& Andrews, D. (2004). The top five reasons for lurking: improving community experiences for everyone. Computers in Human Behavior, 20(2), 201223. doi:10.1016/j.chb.2003.10.015

Rau, P. L. P., Gao, Q., \& Ding, Y. N. (2008). Relationship between the level of intimacy and lurking in online social network services. Computers in Human Behavior, 24(6), 2757-2770. doi:10.1016/j.chb.2008.04.001

Ridings, C., Gefen, D., \& Arinze, B. (2006). Psychological barriers: Lurker and poster motivation and behavior in online communities. Communications of the Association for information systems, 18(1), 329-354.

Ridings, C. M., \& Gefen, D. (2004). Virtual community attraction: Why people hang out online. Journal of Computer-Mediated Communication, 10(1), 00-00. doi:10.1111/j.1083-6101.2004.tb00229.x

Schultz, N., \& Beach, B. (2004). From lurkers to posters. Australian National Training Authority, 14(1), 4-23. 
Shen, K. N., Yu, A. Y., \& Khalifa, M. (2010). Knowledge contribution in virtual communities: accounting for multiple dimensions of social presence through social identity. Behavior \& Information Technology, 29(4), 337-348. doi:10.1080/01449290903156622

Simon, C. D.-K., Brexendorf, T. O. D., \& Fassnacht, M. P. D. (2013). Creating Online Brand Experience on Facebook. Marketing Review St. Gallen, 30(6), 50-59. doi:http://dx.doi.org/10.1365/s11621-013-0299-6

Spender, J. C., \& Grant, R. M. (1996). Knowledge and the firm: overview. Strategic Management Journal, 17(S2), 5-9. doi:10.1002/smj.4250171103

Sun, N., Rau, P. P. L., \& Ma, L. (2014). Understanding lurkers in online communities: A literature review. Computers in Human Behavior, 38, 110-117. doi:10.1016/j.chb.2014.05.022

Takahashi, M., Fujimoto, M., \& Yamasaki, N. (2003). The active lurker: influence of an inhouse online community on its outside environment. Paper presented at the Proceedings of the 2003 international ACM SIGGROUP conference on Supporting group work.

Teece, D. J., Pisano, G., \& Shuen, A. (1997). Dynamic capabilities and strategic management. Strategic Management Journal, 509-533.

Tsai, M. T., \& Cheng, N. C. (2012). Understanding knowledge sharing between IT professionals-an integration of social cognitive and social exchange theory. Behavior \& Information Technology, 31(11), 1069-1080. doi:10.1080/0144929X.2010.550320

Wasko, M. M., \& Faraj, S. (2005). Why should I share? Examining social capital and knowledge contribution in electronic networks of practice. MIS Quarterly, 29(1), 3557. 
Wasko, M. M., Teigland, R., \& Faraj, S. (2009). The provision of online public goods: Examining social structure in an electronic network of practice. Decision Support Systems, 47(3), 254-265. doi:10.1016/j.dss.2009.02.012

Xiang, C. J., Lu, Y. B., \& Gupta, S. (2013). Knowledge sharing in information system development teams: examining the impact of shared mental model from a social capital theory perspective. Behavior \& Information Technology, 32(10), 1024-1040. doi:10.1080/0144929X.2012.745901

Yang, C., \& Chen, L. C. (2007). Can organizational knowledge capabilities affect knowledge sharing behavior? Journal of Information Science, 33(1), 95-109. doi:10.1177/0165551506068135

Yen, C. (2016). How to unite the power of the masses? Exploring collective stickiness intention in social network sites from the perspective of knowledge sharing. Behavior \& Information Technology, 35(2), 118-133. doi:10.1080/0144929X.2015.1105297

Yoon, C., \& Rolland, E. (2012). Knowledge-sharing in virtual communities: familiarity, anonymity and self-determination theory. Behavior \& Information Technology, 31(11), 1133-1143. doi:10.1080/0144929X.2012.702355

Zhao, J., Abrahamson, K., Anderson, J. G., Ha, S., \& Widdows, R. (2013). Trust, empathy, social identity, and contribution of knowledge within patient online communities. Behavior \& Information Technology, 32(10), 1041-1048. doi:10.1080/0144929X.2013.819529 